\title{
Investment in Cost Accounting Systems: Decision Criteria
}

Dr. Linda R. Martin, Economics, University of Hartford Dr. Kathy C. Stevens, Management, Merrimack College

\begin{abstract}
A current debate among accountants focuses on the amount of information collected by traditional cost accounting systems. Critics have said that these systems are inadequate because they provide insufficient detail for optimal decision making and have proposed the adoption of more elaborate cost systems. This paper analyzes cost accounting systems from a cost-benefit perspective and find that in some circumstances traditional methods with their aggregated level of detail are economically optimal.
\end{abstract}

\section{Information As a Costly Investment Good}

Economists have long recognized that the acquisition of information is a costly activity. In the early 1960 s a body of literature emerged which pointed out that investment in information is subject to the same rules as investment in physical assets (Stigler, 1961; Schultz, 1962). The optimal level of information exists when the marginal cost of additional information is exactly equal to its marginal benefit. One implication of information theory is that the optimal amount of information may be less than perfect information.

Accountants also have recognized that information is a costly asset and have questioned the necessity of acquiring additional information. Many research studies have focused on the amount and impact of incremental information contained in new types of required accounting data. For example, FASB \#33, requiring the disclosure of supplemental current cost data, stimulated several investigations into the value of this additional information (Bernard and Ruland, 1987; Shriver, 1987).

A current debate among accountants focuses on the amount of information collected by traditional cost accounting systems. Critics have said that these systems are inadequate because they provide insufficient detail for optimal decision making (Kaplan, 1986). The major thrust of the controversy is that traditional methods of cost accounting have relied on aggregated cost data rather than on specific traceable costs. These averaging methods provide imperfect or incomplete data about the cost of an individual product. Kaplan reports that some firms are now reporting difficulty in making pricing decisions due to increasingly obscure cost estimates; he recommends that firms invest in more elaborate cost systems (Kaplan, 1986). Consultants have reported the installation of such systems but usually these systems were separate and supplemental to the existing cost accounting systems (Brimson, 1987; Frescoln, 1987).

Others have defended traditional cost accounting systems as being economically rational. Horngren (1984 and 1987) has suggested that cost accounting systems must be viewed within the perspective of the costly information model. "The cost-benefit theme is the foundation for judging whether cost accounting systems should be revised." (Horngren, 1984, p. 12). He demonstrates that in some cases incomplete data may be the optimal level of investment in information. For example, when a new product is introduced with a high contribution margin, the firm attempts to sell 
all that it can produce. Since cost is irrelevant to the pricing decision, advanced cost accounting systems will have limited value over traditional systems.

Following Horngren's suggestion, this paper analyzes the debate over the usefulness of traditional cost accounting systems within the framework of the theory of information as an investment good and provides projections for when benefits will be derived from acquiring additional cost information. Using these projections we can identify the conditions under which the more limited data of traditional cost accounting techniques, either job order or process, are as useful for decision making as the more costly, more detailed data collection techniques. The emphasis is on the analysis of the benefit side of the cost-benefit equation. Costs of implementing a new accounting system are assumed to be constant regardless of the benefit. Of course, recent changes in the information supply curve which may be decreasing the cost of acquiring information are also important but will not be considered at this time.

\section{Benefits of Investment in Information}

The impact on the firm from acquiring additional cost information depends on two factors: (1) the extent to which product costs are distorted by current averaging methods; and (2) the degree to which pricing decisions are based on product costs. The effects of relying on average information when specific information is either not available or perceived to be too costly have been investigated by other authors under a variety of conditions. A study on statistical discrimination (the use of group averages to estimate an individual's productivity) indicates that the use of average information causes distortions in labor market behavior (Schwab, 1986). The use of group information discourages able or more productive workers. Shriver (1987) empirically measured the error associated with using a single average price level index instead of several more specific, less aggregated indices and found that the errors lead to an overstatement of product cost. Extending these results to product costing would suggest that the use of current averaging methods would lead to overestimation of cost for the most efficient products.

The benefit of improved cost data rests primarily on whether the firm utilizes the data in pricing decisions. The optimal or profit maximizing price is obtained by equating marginal revenue to marginal cost. In practice, firms utilize many different pricing schemes such as cost-plus pricing, competition-based, and consumer-based pricing. The differences in these strategies depends on the priority the firm attaches to the internal cost environment and the external demand environment. The two polar cases of price strategies are cost-plus pricing with variable cost as the base and consumer-based pricing which relies primarily on the external demand factors.

If traditional cost accounting methods do produce cost data with a systematic error and if these misleading cost figures are used in the price setting process, there will be an incentive to invest resources in a system to increase data collection. However, if either of these conditions is missing, there may be no economic incentive to expand existing data collection systems.

\section{The Model}

We propose to focus on the benefit or value of cost data to a firm. We assume that the expenditure necessary to acquire additional information is fixed and equal to $S$. The value of data is expressed as a function of information. In turn, the amount of information is expressed as a function of the level of data or detailed facts known about product cost.

$$
\text { Value }(\text { data })=\text { V[Information }(\text { data })]
$$

The value (V) depends on both the relationship between data and information as well as on the extent to which the information will be used in decision making. A distinction is made between the concept of information and details of data; information is complete and correct whereas 
details of data are disorganized facts which may be incorrect or incomplete.

We hypothesize that the partial derivative of the value $(\mathrm{V})$ of data is non-decreasing with regard to data.

$$
\begin{aligned}
& \text { Value'(data) } \geq 0 \text { for all values of data, } \\
& \text { data }>0 .
\end{aligned}
$$

Kaplan's assertion of the need for investment in more elaborate cost systems implicitly assumes that the value of the data function is monotonically increasing everywhere;

$$
\begin{aligned}
& \text { Value'(data) }>0 \text { for all values of data, } \\
& \text { data }>0, \text { and } \\
& \text { Value'(data) } \geq S \text {. }
\end{aligned}
$$

This paper explores two possibilities; (1) that the value of additional data may be zero in which case Value'(data) would never exceed S, and (2) that under some conditions Value'(data) is less than S. We attempt to explore the classes of conditions under which either of these cases might be true.

We begin by considering the derivative of equation (3):

$$
\frac{\mathrm{dV}}{\mathrm{dD}}=\frac{\mathrm{dV}}{\mathrm{dI}} * \frac{\mathrm{dI}}{\mathrm{dD}}
$$

The value of the derivative measures the marginal benefit of acquiring additional data. The first part of the derivative, $\mathrm{dV} / \mathrm{dI}$, measures the gain in value to the firm from an increase in cost information whereas the second part, $\mathrm{dI} / \mathrm{dD}$, represents the change in informational content associated with an increase in the amount of cost data.

The value of the total derivative, $\mathrm{dV} / \mathrm{dD}$, depends on the values of the individual derivatives. If both derivatives are positive then it will be true that the value of data is a monotonically increasing function of the amount of data. Hence, more detail is always beneficial but may or may not be greater than $\mathrm{S}$, the marginal cost of implementing an advanced system. However, if there are cases in which either differential is zero, then there are conditions under which the marginal value of additional data is zero. We investigate the possibility that either of these differentials could be zero.

\section{Informational Content of Additional Data}

The derivative $\mathrm{dI} / \mathrm{dD}$ represents the relationship between additional data and additional information. As has been discussed before, a distinction can be made between information which is complete and correct and data which may be incomplete and therefore inaccurate. If additional data leads to an increase in either completeness or accuracy, then the amount of information has been increased. If additional data does not increase completeness or accuracy, then the amount of information has not been increased.

To show whether additional data increases accuracy, we first must investigate the impact of relying on approximate group data to determine if the use of group averages could cause firms to misallocate their own resources. We consider whether there is a systematic error in average cost data due to its incompleteness. If averaging cost data is incomplete, then there will be a potential gain in information associated with increasing the amount of data.

Conceptually, the error associated with relying on aggregated cost data represents the difference between the group average per unit cost, C(Average) and the true but unknown specific product cost $C$ (Detail). This difference which is a measure of the missing information may be expressed as:

$$
\mathrm{E}=\mathrm{C}(\text { Average })-\mathrm{C}(\text { Detail }) \text {. }
$$

This error $\mathrm{E}$ represents an opportunity for a multi-product firm to improve its information by collecting additional data to make the information complete. It should be observed that this error can occur only in a multi-product firm; specialty 
firms do not have this problem because they produce only one good.

To demonstrate the possible magnitude of the error, consider two distinctly separate economies. In both economies several products are manufactured and sold in competitive markets. The economies differ only in the structure of the firms. In one economy there are several multi-product firms. In the other there are many specialty firms each producing only one good. The multi-product firm economy produces the same products as the combined specialty firms' economy. Demand for products is assumed to be the same in both markets.

Consider one firm in the multi-product economy and its counterpart specialty firms from the other economy. For simplicity we limit the products to two good, $i$ and $j$. The individual firms in the specialty economy produce either $i$ or $j$ and the unit cost for each product is given as either $\mathrm{C}(\mathrm{i})$ or $\mathrm{C}(\mathrm{j})$. As each firm produces only one product, these firms know the true unit cost. In contrast, because of some joint activities the multi-product firm cannot costlessly identify its individual product costs; in lieu of this perfect information it substitutes the estimates, $C^{*}(i)$ and $C^{*}(j)$. The multi-product firm uses these estimated costs for decision making purposes.

To simplify the discussion, the argument has been framed generically in terms of a single all-inclusive production cost. In fact, some categories of cost are more easily identifiable by product than others; and in most cases some costs are traceable to individual products while other costs, usually aggregated as overhead, are not. The argument remains the same whether all of the cost is untraceable directly to the product or only part. The magnitude of the distortion will depend on the extent to which the average cost includes untraceable expenses of production.

With traditional cost accounting methods the estimated costs of the multi-product firm, $C^{*}(i)$ and $C^{*}(j)$, are averages based on a linear combination of the true costs weighted by the product mix percentages. Both job order and process costing allocate the untraceable joint cost to product cost on the basis of some proxy. Job order most frequently relies on direct labor hours whereas process costing uses equivalent units of completed product. For ease of exposition this analysis considers the simplest case in which all products are assigned an equal amount of overhead burden. This may be interpreted as representing a job order system in which all products have the same direct labor input or a process cost environment with a single overhead rate.

Let the quantity sold be represented by $Q(i)$ and $\mathrm{Q}(\mathrm{j})$, so that a multi-product firm's product cost can be expressed as:

$$
C^{*}(i)=C^{*}(j)=\frac{[C(i)][Q(i)]+[C(j)][Q(j)]}{Q(i)+Q(j)}
$$

The error in the average cost estimate used by the multi-product firm is the difference between the cost estimate, $C^{*}(i)$ and the true cost $C(i)$. Substituting equation (7) into (6) and simplifying the result yields:

$$
\begin{aligned}
& \mathrm{E}\left[\mathrm{C}^{*}(\mathrm{i})\right]=\mathrm{C}^{*}(\mathrm{i})-\mathrm{C}(\mathrm{i}) \\
& \quad=[\mathrm{C}(\mathrm{i})-\mathrm{C}(\mathrm{j})] \mathrm{X}\{\mathrm{Q}(\mathrm{j}) /[\mathrm{Q}(\mathrm{i})+\mathrm{Q}(\mathrm{j})]\}
\end{aligned}
$$

Similarly, the error in the multi-product firm's estimate of the cost of product $\mathrm{j}$ may be written:

$$
\begin{aligned}
& E\left[C^{*}(j)\right]=C^{*}(j)-C(j) \\
& \quad=[C(j)-C(i)] X\{Q(i) /[Q(i)+Q(j)]\}
\end{aligned}
$$

A review of equations 8 and 9 allows some initial analysis of the potential error from relying on averages. Three implications can be inferred.

IMPLICATION A: The magnitude of the error from relying on average data is positively related to the difference between the true cost functions for the two products, $[\mathrm{C}(\mathrm{j})-\mathrm{C}(\mathrm{i})]$. Hence, the potential gain from improving the data collection system is the greatest for two products with very different cost functions. 
In the polar case of homogeneity with regard to cost functions, $C(i)$ would be the same as $C(j)$ and the difference between them zero. In this special case, the aggregated data of traditional cost accounting systems would be just as useful as specific data since the error in both $C^{*}(\mathrm{i})$ and $\mathrm{C}^{*}(\mathrm{j})$ would be zero. There would be no marginal benefit associated with improving the information to justify further investment.

This distinction between products with homogeneous and heterogeneous cost functions exists in a primitive way in cost accounting. The criterion for choosing between process costing and job order costing is the heterogeneity of the products. When product characteristics are different, job order is preferred. In contrast, when the products are homogeneous, process costing is recommended. If homogeneous products have homogeneous cost functions, then it might be predicted that in industries using process costing there would be relative contentment with traditional cost accounting techniques because $\mathrm{dI} / \mathrm{dD}=0$. If heterogeneous products are more likely to have heterogeneous cost functions, then it might be predicted that industries using job order costing would more likely exhibit dissatisfaction with traditional cost accounting techniques.

IMPLICATION B: The sign of the error in $C^{*}(i)$ will be opposite to the sign of the error in $C^{*}(\mathrm{j})$. In this two product situation, the use of average costs in place of exact costs results in an underestimation of one product's costs and an overestimation of the other product's costs. The analysis can be expanded to a general case of a multi-product firm producing two classes of products. One group of goods' costs will be underestimated while other product's costs will be overestimated.

IMPLICATION C: The magnitude of the error in $C^{*}(i)$ or $C^{*}(j)$ will be influenced by the product mix. The size of the error in $C^{*}(i)$ is inversely related to quantity of product $\mathrm{i}$ that is produced. As more of a good is produced the size of the error in unit cost decreases. When costs are misallocated between groups of products, the smallest group of products bears the largest per unit impact of the error.

The three implications show that the use of average costs instead of exact costs by a firm producing multiple products will result in errors in cost estimates as long as the production processes differ among the goods. Under these conditions $\mathrm{dI} / \mathrm{dD}>0$ and the magnitude of $\mathrm{dI} / \mathrm{dD}$ is directly proportional to the degree of product cost diversity.

\section{The Influence of Cost Information on Pricing Decisions}

Next we consider the sign of $\mathrm{dV} / \mathrm{dI}$ to determine the value of information to a firm. Under what conditions is the differential likely to be positive and under what conditions, if any, is the value likely to be zero. Horngren [1984] has pointed out that in some circumstances firms do not use or are little affected by the product cost data when making decisions. Hence, imperfect data has no direct effect on optimality or profitability and reducing the error will be of no benefit to the firm.

As previously stated the price setting decision of most business firms are dependent on two factors: (a) product cost data (or the internally derived manufacturing data), and (b) demand (or the external environmental factors such as consumers' tastes and preference, income, and industrial competition). The value of additional cost information depends on the firm's pricing strategy. Only companies which use cost-plus pricing (or some variant) will benefit from reducing the error in product cost data. Firms that use reactive, follow-the-leader or demand based strategies will not benefit because costs have no impact on price and hence, $\mathrm{dV} / \mathrm{dI}=0$.

To demonstrate the extent and effect of imperfect cost information on decision making of firms utilizing cost-based pricing schemes, we will consider the same two economy model as before. Multi-product firms which use a pricing strategy based on their internal cost data may set prices 
which are non-profit maximizing. The specialty firms do not have this problem because they know the exact cost. The selling prices in each market can be summarized in the following equations:

\section{$\underline{\text { Product } \mathrm{i}} \quad$ Product $\mathrm{j}$}

$$
\begin{array}{lll}
\text { multi-product: } & P^{*}(i)=C^{*}(i)+m[e(i)] & P^{*}(j)=C^{*}(j)+m[e(j)] \\
\text { specialty: } & P(i)=C(i)+m[e(i)] & P(j)=C(j)+m[e(j)]
\end{array}
$$

where $\mathrm{m}(\mathrm{e})$ is the mark-up percent which is a function of the elasticity (e) of demand for the product. Since consumer demand is assumed to be the same in both economies, the optimal mark-up percent would be the same for both firms. Errors in pricing $\left[\mathrm{P}^{*}(\mathrm{i})-\mathrm{P}(\mathrm{i})\right.$ and $\mathrm{P}^{*}(\mathrm{j})$ $P(j)]$ arise solely from errors in estimated costs.

If the multi-product firm overestimates the cost of $i$, then its market price, $\mathrm{P}^{*}(\mathrm{i})$ will be higher than the market price of $i$ offered by the specialty firm, $\mathrm{P}(\mathrm{i})$. Moreover, because the cost of $\mathrm{j}$ has been correspondingly underestimated, its market price, $\mathrm{P}^{*}(\mathrm{j})$ will be lower than the market price of the specialty firm, $P(j)$. Sales of $i$ will be lower and sales of $j$ will be higher than the optimal profit maximizing amounts.

These pricing errors can also have an effect on total profitability if the firm uses individual product profit analysis as a decision criteria about the firm's product mix. An underestimate of a product's cost means an overestimate of its contribution margin for a given price. A decision to increase its sales volume based on an overestimated contribution margin could lead to unexpected and unpleasant surprise when net income is calculated at the end of the period.

The value of $d V / d I$ is then dependent on the extent of utilization of cost in the decision making process. The greater the reliance on cost information, the more valuable information becomes to a firm and the more likely $\mathrm{dV} / \mathrm{dI}>\mathrm{S}$.

\section{Summary}

This paper has viewed cost accounting systems through the lens of a cost-benefit perspective and found that in some circumstances traditional methods with their aggregated level of detail are economically optimal. Kaplan's call for greater detail in cost accounting systems is relevant only for some firms. Under certain conditions, the optimal level of investment in information for decision making may be aggregated and allocated (i.e., imperfect) data.

This paper outlined some conditions under which imperfect information may be economically optimal. When the first derivative of the value function is zero, acquiring additional cost data has no value to the firm. This condition is true when: (a) production processes and cost functions are homogeneous, and (b) management of the firm uses demand-based pricing schemes exclusively.

In all other cases the marginal benefits from increased data collection are positive. However, the marginal benefits will be small whenever: (a) there is little diversity among production processes, and (b) there is only a small reliance on the internal cost environment when pricing decisions are made. In such cases the anticipated marginal benefits would most likely be less than $\mathrm{S}$ (the cost of implementing such systems), and the optimal decision would be to not invest in detailed cost accounting systems. 


\section{References}

Bernard, V. L. and R. G. Ruland, "The Incremental Information Content of Historical Cost and Current Cost Income Numbers: Time Series Analyses for 1962-1980," Accounting Review, Vol. 62, No. 4, pp. 707-722, 1987.

2 Bowen, R. M.; D. Burgstahler, and L. A. Daley, "The Incremental Information Content of Accrual Versus Cash Flows," Accounting Review, Vol. 62, No. 4, pp. 723-747, 1987.

3 Brimson, James A. "Live Case Studies" presented at the National Association of Accountants, Cost Accounting for the '90s: The Challenge of Technological Change Conference, Montvale, N. J., 1987.

4 Douglas, Evan J., Managerial Economics, 3rd. ed., Prentice-Hall, Inc. Englewood Cliffs, N.J., 1987.

5 Frescoln, Leonard D. "Live Case Studies" presented at the National Association of Accountants, Cost Accounting for the '90s: The Challenge of Technological Change Conference, Montvale, N. J., 1987.

6 Horngren, Charles T., "Cost and Management Accounting: Yesterday and Today," unpublished manuscript, Stanford University, 1984.

7 Horngren, Charles T. and Gary L. Sundem, Introduction to Management Accounting, 7th ed., Prentice-Hall, Englewood Cliffs, N. J., 1987.

8 Kaplan, Robert S., "Accounting Lag: The Obsolescence of Cost Accounting Systems," California Management Review, Vol. 28, No. 2, pp. 174-199, 1986.

9 National Association of Accountants, Cost Accounting, Robotics, and the New Manufacturing Environment Conference Proceedings, Montvale, N. J., 1987.

10 Schultz, Theodore, editor, "Investment in Human Beings," Journal of Political Economy, Vol. 70, Supplement, pp. 1-157, 1962.

11 Schwab, Stewart, "Is Statistical Discrimination Efficient?" American Economic Review, Vol. 76, No. 1, pp. 228-234, 1986.

12 Shriver, Keith A., "An Empirical Examination of the Potential Measurement Error in Current Cost Data," Accounting Review, Vol. LXII, No. 1, pp. 79-96, 1987.

Stigler, George, "The Economics of Information," Journal of Political Economy, Vol. 69, No. 2, pp. 213-225, 1961. 